\title{
The transmission of Helicobacter pylori: The effects of analysis method and study population on inference
}

\author{
Wayne Delport $\mathrm{PhD}^{\mathrm{a}}$, Postdoctoral Fellow and Schalk W. van der Merwe MBChB, BSc (Hons), MSc \\ (Physiology), MMed Internal Medicine, $\mathrm{PhD}$, b, , Associate Professor of Immunology
}

${ }^{a}$ DST-NRF Centre of Excellence at the Percy FitzPatrick Institute, University of Cape Town, Rondebosch 7701, South Africa ${ }^{b}$ Department of Immunology, Hepatology/GI-Research Laboratory, University of Pretoria, Pretoria 0002, South Africa

Although much is known about the virulence of Helicobacter pylori, the transmission pathways for this bacterium are still unresolved. Transmission has been addressed through: (1) prevalence within families; (2) detection in fecal/oral environments; (3) detection in the abiotic/biotic environment; and (4) direct inference from strain similarity. Here, we review the molecular and biochemical methods used and discuss the relative merits of each. Furthermore, as there are differences between developing and developed nations, we discuss the results obtained from transmission studies in light of the study population. We conclude that $H$. pylori is probably transmitted person-to-person, facilitated by fecal-oral transmission during episodes of diarrhea or gastro-oral contact during periods of vomiting. The persistence of $H$. pylori in abiotic and biotic environments remains unproven but possible reactivation from viable, non-culturable coccoid forms should be further investigated. Finally, we speculate on the effect of host-pathogen interactions in confounding the inference of transmission.

\section{Introduction}

The transmission of bacterial pathogens is an important area of research both in developed and in developing countries. Understanding this process is pivotal for the planning of suitable and efficient treatment regimes for the eradication or control of such pathogens. However, transmission of bacterial

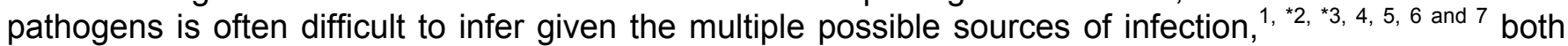
abiotic and biotic reservoirs, $4,5,6,8,9$ and 10 the array of detection methods with varying levels of sensitivity, ${ }^{*}$ and 11 and the potentially confounding effects of the host's immune response. Although much progress has been made in addressing $H$. pylori transmission, it's study is complicated by these factors. Here we review the current knowledge of $H$. pylori transmission with two central themes in mind. First, we consider the differences between developing and developed countries. Poor sanitation, overcrowding, and generally low socioeconomic status determine susceptibility to $H$. pylori infection. ${ }^{12,13}$ and 14 Furthermore, developing countries show a much higher prevalence of infection, in some cases epidemic proportions of up to $80 \%$ of the population are infected. ${ }^{15,16}$ and ${ }^{*} 17$ Therefore, it is crucial to interpret the results from a study of transmission in light of the socioeconomic characteristics of the study population. Second, the sensitivity of an $\mathrm{H}$. pylori detection method is likely to cause discrepancies in the inference of transmission. Transmission of $H$. pylori has been evaluated with: the presence/absence of antibodies, ${ }^{18}$ and ${ }^{19}{ }^{13} \mathrm{C}$ urea breath tests, ${ }^{18}$ and 20 restriction-enzyme digestion of amplified genes, ${ }^{21}$ analyses of peptide sequences, ${ }^{22}$ and high-resolution nucleotide sequence analysis. ${ }^{* 17,23}$ and 24 Methods that compare nucleotide sequences across pedigrees to infer transmission offer a higher resolution than methods based on presence/absence. Therefore, the results of a transmission study should be evaluated critically in terms of the methods used. 


\section{Biochemical and molecular methods}

The methods used in transmission studies can be subdivided into: (1) presence/absence methods; (2) low-resolution molecular methods; (3) mid-resolution molecular methods; and (4) high-resolution molecular methods. Each of these methods has strengths and weaknesses that should be considered in relation to the intended objective of the transmission study.

\section{Presencelabsence}

Presence/absence methods identify $H$. pylori through a variety of approaches. Antigen-based tests identify the presence of an $H$. pylori-specific antibody directed at an $H$. pylori antigen, and thus are specific for the detection of $H$. pylori. Enzyme-linked immunosorbent assay (ELISA) is often utilised. This has the advantage of detecting the presence of an antigen (through antibody binding) and the concentration of antibodies (through an enzyme-linked antibody). The sensitivity and specificity of ELISA are, however, dependent on the antibody used and it often remains necessary to evaluate this against other methods in a focal study population. Specifically, previous studies have shown that $H$. pylorispecific IgM antibody responses can be highly variable, occurring in less than $20 \%$ of children and developing between 2 weeks and 3 months of infection. ${ }^{25}$ In experimentally infected adults, $80 \%$ of the volunteers developed IgM antibody responses within 2-4 weeks. By contrast, this particular study demonstrated that anti- $H$. pylori lgG responses appeared only 4 weeks after exposure and peaked at 12-19 weeks. ${ }^{26}$ This suggests that absence of $H$. pylori-specific antibody responses, especially in children, can obscure transmission and might result in an underestimation of prevalence. ${ }^{27} \mathrm{H}$. pylorispecific antigens can also be detected in stool as an indication of active disease. $H$. pylori antigens can be detected by both polyclonal and monoclonal capture antibodies; the monoclonal antibody assay has been shown to be highly sensitive $(92 \%)$ and specific $(70 \%) .^{28}$

${ }^{13} \mathrm{C}$ urea breath tests ${ }^{29}$ rely on the conversion of ingested ${ }^{13} \mathrm{C}$ urea - by hydrolysis - into ${ }^{13} \mathrm{CO}_{2}$ and ammonia by $\mathrm{H}$. pylori. These are readily detectable in a breath sample from an infected individual. Breath tests have been shown to be highly sensitive and specific and are now commonly employed to confirm both active infection and eradication after antibiotic therapy. ${ }^{30}$

The presence of $H$. pylori can also be shown in histological specimens obtained at endoscopy after appropriate staining. ${ }^{30}$ Previously regarded as the gold standard to confirm active $H$. pylori infection, this has largely been replaced by non-invasive tests.

Finally, polymerase chain reaction (PCR) that targets an $\mathrm{H}$. pylori-specific gene can be used to confirm the presence of $H$. pylori. Once again, sensitivity and specificity of the chosen gene in the study population should be evaluated against a more specific approach. However, PCR has been shown to be both highly sensitive and highly specific ${ }^{* 2}$ and 31 for the detection of $H$. pylori. ${ }^{32}$ The presence/absence methods currently utilised are mostly sufficient to address prevalence of $H$. pylori within populations.

Several methods - such as urea breath tests, ELISA, and PCR - have been extensively tested and showed to have good correlations with histopathological results. However, a limitation of presence/absence methods needs to be addressed, namely, that these methods evaluate only the presence of $H$. pylori and do not provide any information regarding strain similarity between individuals. Therefore, they are useful only for evaluating factors that influence prevalence within populations. In populations with a low incidence of $H$. pylori, prevalence can be used as a proxy for interpreting transmission, whereby increased prevalence among family members suggests an intrafamilial transmission route. ${ }^{18,20}$ and 33 When incidence in a study population is high, it is necessary to evaluate the degree of strain similarity between individuals to make inferences of transmission. In such cases, the use of molecular methods is proposed. These identify the degree of strain-sharing between related individuals and thus can be used to infer the routes of transmission. However, molecular methods vary in the resolution to which strains can be reliably identified. Here we consider low-, mid-, and high-resolution molecular methods. 


\section{Low-resolution molecular methods}

Low-resolution molecular methods can detect molecular differences between strains. Typically, these methods comprise an imunoblot, whereby denatured proteins are separated by gel electrophoresis and probed using specific antibodies. Differences between strains are detectable as differences in the mass of the denatured proteins. The methods are low resolution because the proteins highlighted are typically similar in both function and mass between strains.

\section{Mid-resolution molecular methods}

Molecular methods that utilise restriction-enzyme digestion offer improved resolution over those that utilise electrophoresis to separate proteins by mass.

Restriction fragment length polymorphisms (RFLP) comprise the restriction-enzyme digestion of chromosomal, or PCR amplified, DNA. Essentially, endonucleases that recognise a particular DNA sequence motif are used to cut DNA at these recognised sites. The resulting fragments are subsequently separated by gel electrophoresis, such that a unique DNA profile or fingerprint is achieved. Similarity of strains is evaluated as a degree of band or fragment sharing.

Ribotyping, which is often used in H. pylori studies, refers to the digestion of chromosomal, non-amplified DNA by the Haelll restriction enzyme.

Pulsed-field gel electrophoresis (PFGE) is a variation of gel electrophoresis of restriction-enzymedigested chromosomal DNA. ${ }^{34}$

Random amplification of polymorphic DNA (RAPD) comprises the random PCR amplification of genomic DNA with random generated primers. RAPDs are useful for poorly characterised organisms because little or no prior molecular information is required.

The typeability and discriminatory power of these mid-resolution methods have been evaluated. ${ }^{11}$ Typeability is the ability of the method to provide an unambiguous result, whereas discriminatory power refers to the ability of the method to identify non-related strains or isolates. ${ }^{35}$ The authors ${ }^{11}$ concluded that restriction-enzyme methods based on chromosal DNA (ribotyping, PFGE) are sensitive to DNA concentrations, DNA quality and incomplete DNA digestion, and thus have lower typeability (12.5-66\%). Yet typeabilities of $100 \%$ are typically achieved for PCR restriction-enzyme digestions and RAPDs. ${ }^{11}$ However, given inconsistencies in the reproducibility of RAPDs in different laboratories, ${ }^{36,37 \text { and } 38}$ the use of PCR RFLP is recommended. ${ }^{11}$ Although, PCR RLFP provides both good typeability and good discriminatory power, the method provides only an overall degree of similarity between two isolates. Given that mutations can occur at sites other than those involved in restriction-enzyme digestion, differences between isolates can go undetected. Such undetected genetic variation might not be problematic when evaluating within-population genetic diversity, yet it can confound results when evaluating direct person-to-person transmission of $H$. pylori. In such cases, high-resolution molecular methods are preferred.

\section{High-resolution molecular methods}

High-resolution molecular methods include DNA sequencing of single genes and multi-locus sequence typing (MLST). These methods offer an advance over previous approaches because mutations are observed directly and multiple sites are considered. In addition, the inclusion of multiple loci or genes in multi-locus sequence typing allows the inference of recombination. ${ }^{39}$ Although sequencing provides the highest resolution for the detection of strain or isolate similarity, the processes of mutation and recombination can complicate the analyses of such sequences. 


\section{Data analysis}

In addition to the molecular/biochemical approach used to detect and compare strains of $H$. pylori, it is necessary to consider the subsequent statistical or data analysis approaches. Generally, transmission has been inferred from three categories of data analysis: logistic regression, phylogenetic reconstruction, and custom-model development.

\section{Logistic regression}

The logistic regression approach has the purpose of identifying the predictor variables that contribute significantly to a response variable. Predictor variables can be factors such as familial infection status, poor hygiene, social crowding, age, and race; response variables are typically the prevalence of $H$. pylori as determined with presence/absence methods. Logistic regression has been used extensively both to infer intrafamilial transmission ${ }^{20,40}$ and 41 and to identify factors that contribute to the prevalence of $H$. pylori. ${ }^{42}$ and 43 However, potential problems with this approach for the inference of transmission is the distinction between cause and effect. For example, several studies have identified the infection status of

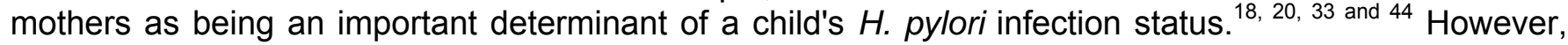
relatively few studies consider the role of an external environmental source, such as a common water source used by both mother and child, as a factor determining $H$. pylori transmission. Thus the potential cause of a correlation in mother's and child's infection status is not considered and a potentially misleading conclusion is drawn. It should therefore be borne in mind that logistic regression studies merely indicate that the significantly correlated factors are the main contributing factors only of those considered in a particular study.

\section{Phylogenetic reconstruction}

Phylogenetic reconstruction, based on DNA sequence data, has been used to identify transmission as the clustering of within-family strains on a phylogenetic tree (Figure 1). Individuals who cluster within a phylogenetic tree are genetically similar and therefore are inferred to share a common ancestor, or to represent a transmission event. Phylogenetic studies have generally supported intrafamilial transmission of $H$. pylori because strains from individuals within families are much more tightly clustered than strains from the community. However, a phylogenetic approach might not be appropriate because $H$. pylori exhibits a high rate of recombination, ${ }^{39}$ which results in adjacent nucleotides along a DNA sequence having different evolutionary histories (Figure 1a). Therefore, phylogenies derived from strains of $H$. pylori based on different genes can suggest different transmission pathways (Figure 1). Sequencing of two genes (ureC and mutY, Figure $1 \mathrm{~b}$ ) from individuals within an African community ${ }^{17}$ showed clear recombination events that made inference of transmission using phylogenetic methods difficult. In this study, two individuals (R1 and R2) clustered on alternate branches of the phylogeny, depending on which gene was used. A recombination break-point is therefore inferred to have occurred between these two genes, creating alternative inferences of transmission on each side of this break-point. Recombination events can also be detected within a single gene (Figure $1 \mathrm{~b}$ ) as strains with similarity to both of the major phylogenetic groups within the community (R3-R5, Figure 1b). As recombination can clearly influence the inference of transmission, methods that infer transmission pathways and incorporate recombination into the analyses are proposed. 

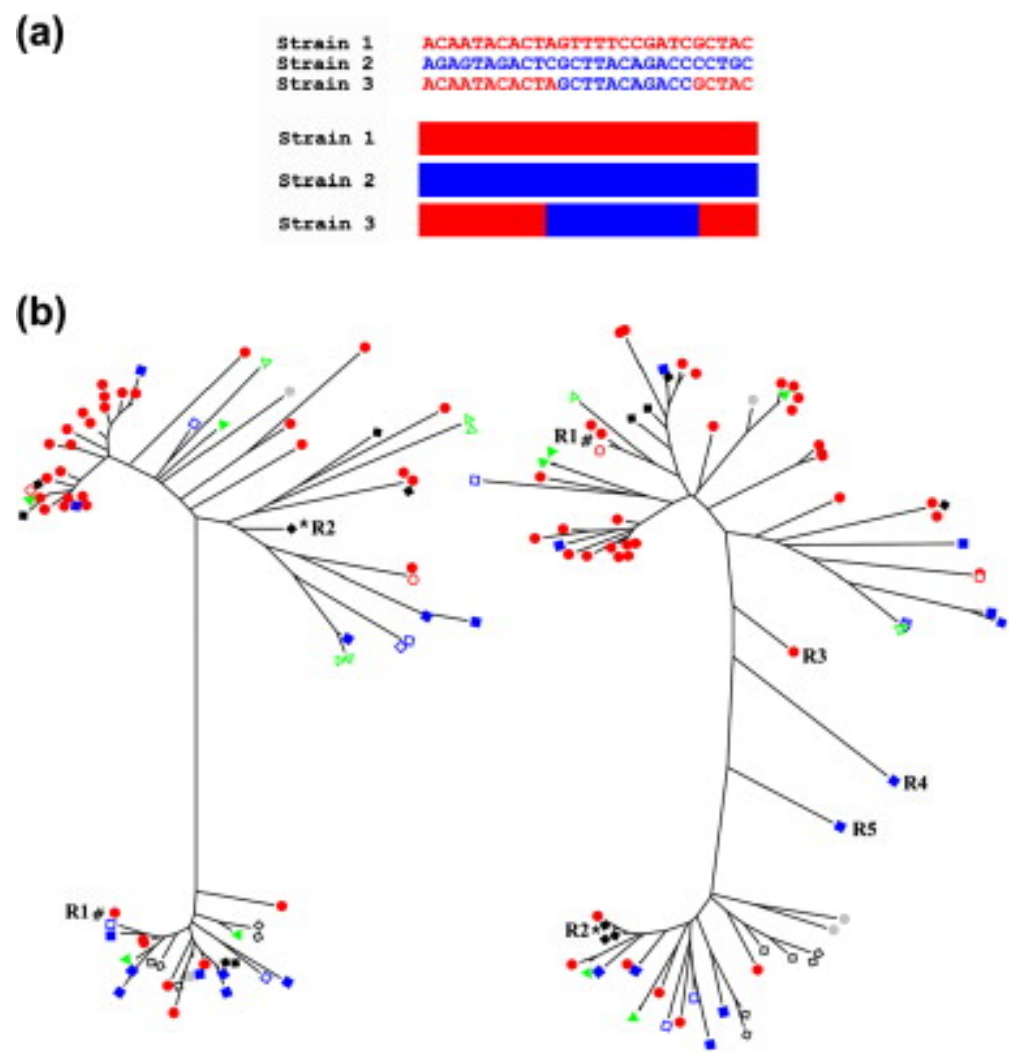

Figure 1. The use of phylogenetic methods to infer transmission, and the effects of recombination. (a) Recombination that results in a strain with two independent evolutionary histories is shown. Strain 3 is a clear recombinant of strains 1 with 2 . (b) The effects of recombination on transmission inference using phylogenetic methods in which unrooted neighbour-joining phylogenetic trees constructed from two genes (left to right: ureC and mutY) are shown. Clear recombination events are indicated where individuals R1 and R2 have alternate placements in the phylogeny for the two genes sequenced, and thus have different inferred evolutionary histories. Recombinant individuals R2-R5 represent recombination events between the two predominant phylogentic clusters evident at the top and bottom of the phylogenies. Colored symbols represent families, where no clear clustering of individuals from the same family is evident.

\section{Custom-model development}

One approach to identifying a common source of infection is the identification of the same or similar strain, through DNA sequencing, in multiple individuals. For instance, a mother and child harboring the same strain, as identified with DNA sequencing, would result in the inference of mother-to-child transmission. However, given that $H$. pylori has both high mutation and recombination rates, ${ }^{39}$ it is likely that two individuals harboring slightly divergent strains of $H$. pylori have a common source of infection. This potential exists because mutation and recombination events might have occurred - in either or both individuals - between the time of infection and that of subsequent sampling for DNA sequences. Indeed, such within-individual evolutionary changes are supported by longitudinal studies based on paired samples. ${ }^{45,46,47 \text { and }{ }^{*} 48}$ In such cases, a model that incorporates mutational and recombination changes should be used to infer transmission. Thus far, only one study has addressed the potential confounding effects of mutation and recombination. ${ }^{17}$ Here, a custom model was developed that simulated transmission of $H$. pylori strains and their gene sequences within a community. Such an approach allows the comparison of observed levels of DNA sequence divergence within families, households, or communities with the level simulated under a hypothesised transmission route. Such comparisons allow the inference of transmission, corrected for the potential confounding effects of mutation and recombination. 


\section{Transmission in developing and developed countries}

The biochemical, molecular, and analytical methods discussed above have been used to address a number of important components of transmission, including: (1) factors positively correlated with $\mathrm{H}$. pylori prevalence; (2) the relative importance of fecal-oral and oral-oral pathways in transmission; (3) the role of biotic and abiotic reservoirs; and (4) the inference of an individual's source of infection and thus the most likely transmission pathways, within both developed and developing countries.

\section{Factors correlated with prevalence}

First, the pattern of infection status across individuals has allowed the identification of population specific or environmental factors that are positively correlated with prevalence. These studies support social crowding, ${ }^{25,43,49,50}$ and 51 low socioeconomic status, ${ }^{6,50,51,52}$ and 53 age, ${ }^{25,42,43,50}$ and 52 and race ${ }^{52}$ as important determinants of the prevalence of $H$. pylori. Although these studies have used only presence/absence methods for inference, this is sufficient to identify factors that are correlated with $H$. pylori infection. Correlation of prevalence with both social crowding and low socioeconomic status suggest person-to-person transmission of $H$. pylori, which lends support to the higher prevalence observed in developing countries. ${ }^{54}$ Statistical correlation of increased prevalence with age and race, however, require further clarification.

Several studies support the notion that age is an important determinant of $H$. pylori prevalence. Indeed, $71 \%$ of Peruvian children studied by ${ }^{13} \mathrm{C}$ breath testing were positive by the age of 6 months. ${ }^{9}$ Similarly, high rates of early acquisition have been reported from other developing countries, including Bangladesh, ${ }^{55}$ and ${ }^{56}$ Gambia, ${ }^{57}$ and China. ${ }^{25}$ In developed countries, however, the prevalence of early infection seems to be substantially lower, with only $1.2 \%$ of Swedish children being seropositive at 6 months $^{58}$ and only $8 \%$ of American children aged $1-3$ years. ${ }^{59}$ Seroconversion in both developed and developing countries peaks at $3-5$ years of age, ${ }^{60}$ suggesting that the human stomach is most susceptible to infection at this time. However, one study reports a median seroconversion age of 7.5 years in developed countries, and the continuation of acquisition of infection into adulthood. ${ }^{59}$ Given that seroconversion peaks at 3-5 years, the positive correlation of age with prevalence in studies involving young children ${ }^{6,42,43}$ and 52 is not surprising. However, given that urea breath testing might have reduced specificity in young children ${ }^{61}$ and 62 and the lack of validation of stool antigen testing in young children, ${ }^{27}$ such age-related effects might simply be the result of reduced detection ability. The positive correlation of age with prevalence in adult study populations ${ }^{63}$ and 64 might be attributed to compromised living conditions, such as occurred during the Second World War, ${ }^{64}$ and substantial improvements in socioeconomic conditions in developed countries, known as the cohort effect. ${ }^{63}$ and 65

Early acquisition of infection is also associated with a higher rate of subsequent loss of infection, ${ }^{58}$ and 59 with up to $80 \%$ of infections being lost without intervention. ${ }^{58,66}$ and 67 However, reinfection is common and although there do not seem to be sex differences in the acquisition of $H$. pylori or in the rate of loss of infection, ${ }^{59}$ clear racial differences have emerged. Black children have been found to have a higher rate of initial acquisition, a lower rate of loss of infection and a higher rate of reinfection than white children, although the study did not correct for socioeconomic status between the groups. ${ }^{59}$ However, it is still not known whether susceptibility to infection is host specific (Figure 2) or if social factors, including a high infectious burden in communities and families, is responsible for this phenomenon. ${ }^{68}$ 


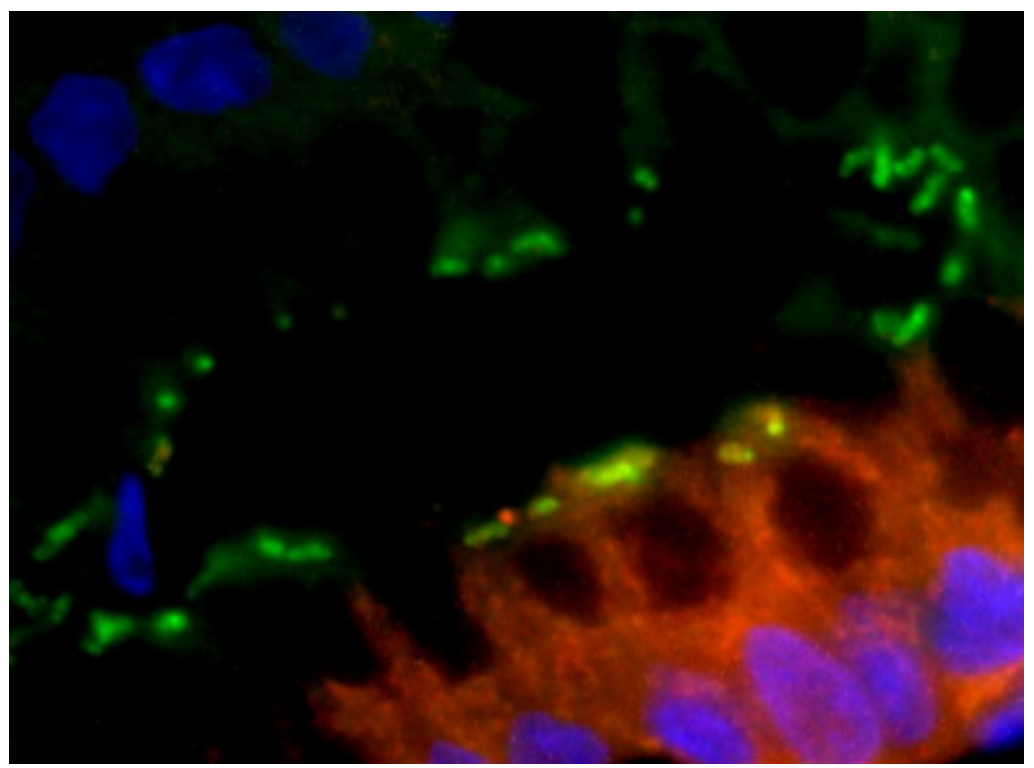

Figure 2. Fluorescent in-situ hybridization (FISH) detection of $H$. pylori in an infected African individual showing the burden of $H$. pylori disease with multiple organisms visible.

\section{Person-to-person transmission modes}

The general consensus is that transmission occurs from person to person, although it is unclear whether such transmission is direct from one person to another or is mediated via a common source associated with social crowding. Thus, much effort has been directed at identifying the person-to-person mode of transmission, through examination of the relative potential for feces and mouth-borne $H$. pylori to initiate infection. Such studies need to be evaluated in terms of the methods used and prevalence within the study population.

\section{Oral-oral transmission}

The role of the oral cavity as a reservoir from which $H$. pylori can spread remains highly controversial (see ref. 2 for an extensive overview). H. pylori would need to survive in a hostile environment shared with bacteria, fungi, and viruses. Further, as a slow-growing, fastidious bacterium, $H$. pylori would need to compete against many fast-growing bacteria and face the antibacterial properties of saliva. Despite this, studies using PCR amplification of DNA fragments have demonstrated the presence of $H$. pylori in the mouth. ${ }^{69,70,71,72 \text { and } 73}$ However, the organism has rarely been cultured from samples from the mouth ${ }^{69}$ and some studies have been unable to detect it there. ${ }^{16}$ These apparent discrepancies - between positive and negative results - are difficult to explain on scientific merit alone. Thus the cardinal questions relate to: (1) the mouth as a transient versus permanent reservoir related to an individual's disease state; and (2) the extent to which differences both in study population and methods used can explain discrepancies between studies evaluating the role of the mouth environment in transmission.

Colonization of the mouth by $H$. pylori has been shown by both culture ${ }^{69}$ and PCR. ${ }^{69,71}$ and 74 However, studies have not been able to differentiate transient colonization of the mouth after induced vomiting or as the result of gastrointestinal disease from permanent colonization where the mouth acts as a reservoir. Indeed, most studies that have shown $H$. pylori DNA in mouth samples have involved hospitalised individuals or individuals presenting to gastrointestinal clinics, ${ }^{75}$ or have been performed after induction of vomiting. ${ }^{69}$ This suggests that the presence of $H$. pylori in oral samples might not be sustained and could be transiently affected by illness, and thus is not representative of a general healthy population. Indeed, when the oral presence of $H$. pylori was studied in a high-prevalence healthy population using validated PCR methods after optimization of sample collection and DNA isolation, no $H$. pylori DNA could be amplified. ${ }^{16}$

Cultural and social differences, such as the shared use of chopsticks in Eastern countries ${ }^{76}$ and the premastication of food in African cultures ${ }^{77}$ might explain some of the population differences. $H$. pylori 
might also prefer certain niches within the mouth environment and this could have resulted in sampling error in some studies. ${ }^{70}$ The role of the mouth environment in transmission has been evaluated using both PCR and culture. However, the detection of $H$. pylori in the mouth by PCR does not imply a potential route of transmission as $\mathrm{H}$. pylori has been shown to occur in a coccoid form that is detectable with PCR yet is not culturable. ${ }^{78}$

In addition, DNA extraction methods and the resultant quality of DNA obtained from mouth samples can vary. For instance, DNA obtained from saliva pellets after centrifugation have been shown to be inferior compared to DNA obtained from saliva directly placed into digestion buffer ${ }^{79}$ Olivier and co-workers ${ }^{16}$ have shown the importance of assessment of DNA quality prior to DNA amplification. Inhibitors might exist in the mouth, preventing amplification and leading to false-negative results. Thus all negative samples should be spiked with $H$. pylori DNA prior to amplification. Finally, the sensitivity and specificity of primers have been reported to vary ${ }^{75}$ permitting the amplification of non- $H$. pylori DNA. Therefore, sensitivity of primers and PCR methods should be evaluated and the amplicons generated should be subjected to sequencing to confirm sensitivity.

Low quantities of $H$. pylori have been shown to occur in the saliva of healthy controls, yet the clinical significance of this finding is uncertain. ${ }^{69}$ Some evidence of the role of the mouth environment in transmission is provided by studies investigating the prevalence among spouses. ${ }^{7}$ and 80 Epidemiological data have shown that $H$. pylori-infected individuals who have been treated are not reinfected by their partners. ${ }^{81}$ In addition, very divergent $H$. pylori strains are commonly found between partners, suggesting that the oral-oral route is unlikely to be an important mode of transmission. ${ }^{80}$

In conclusion, the fact that few studies have detected culturable $H$. pylori in the mouth environment suggests that the mouth is unlikely to act as a permanent reservoir. However, it might act as temporary route of transmission during gastrointestinal disease. Furthermore, it is unlikely that the mouth environment plays a substantial role in transmission in healthy asymptomatic populations. Therefore, other modes of transmission should be considered to account for high prevalence of $H$. pylori in many developing nations. ${ }^{54}$

\section{Fecal-oral transmission}

The fecal-oral route is another potential route of transmission. It is difficult to detect the presence of $H$. pylori in fecal samples because of the potential for inhibitors to block DNA amplification (see ref. 2 for review). Immunomagnetic separation, in which magnetic beads coated with $H$. pylori antibody capture (and thus concentrate) $H$. pylori in stool, has been used to reduce the effect of inhibitors. Parsonnet and co-workers $^{69}$ report that $H$. pylori DNA can be amplified from normal stool samples in a third of individuals, yet no $H$. pylori could be cultured from these individuals. Conversely, $H$. pylori DNA could be amplified from $69 \%$ of individuals with induced diarrhea and stool cultures were positive at least once in $50 \%$ of these individuals. These findings suggest that slow passage through the gastrointestinal tract might reduce the pathogenic potential of $H$. pylori. Indeed, $H$. pylori could be cultured from the stool samples of rural Gambian children with diarrhea, ${ }^{82}$ supporting the notion that fast passage through the gastrointestinal tract does not limit the pathogenic potential of $H$. pylori.

In summary, current understanding suggests that $H$. pylori is unlikely to survive a slow passage through the gastrointestinal tract due to immense pressures from competing bacteria, but that it might readily be excreted during episodes of diarrhea. The differential role of oral-oral versus fecal-oral transmission is stressed, with studies showing that gastroenterologists are at higher risk of infection ${ }^{83}$ and 84 than dental workers. $^{85}$ and 86 Therefore, oral-oral transmission does not appear to play a substantial role in transmission - except during times of vomiting, when transmission is essentially gastro-oral. Distinguishing between oral-oral and gastro-oral routes would prevent further confusion arising from differences in the inferred role of the mouth in healthy versus symptomatic individuals. Finally, we advocate that the fecal-oral route plays a more substantial role given that diarrhea, which is associated with malnutrition and infections, is common in developing countries. 


\section{Abiotic and biotic reservoirs}

$H$. pylori is a pandemic infection. This suggests the existence of multiple transmission routes and also that $H$. pylori infection can occur from the environment. Although $H$. pylori has been detected - using molecular methods - in various water systems (including rivers, surface and shallow ground water, 8 and 87 and sewage systems ${ }^{88}$ ), it could only rarely be cultured from these sources. The questions that accompany these finding relate to their clinical implications: Detection of $H$. pylori DNA in water sources does not necessarily confirm viability and infectivity. However, it has recently been shown that $H$. pylori, like other related bacteria, such as Vibrio, might enter into a viable but not culturable state. ${ }^{89}$ This state probably corresponds to the coccoid form, which exists during periods of stress and nutrient depletion in experimental laboratory conditions. ${ }^{90}$ Recently, Adams and co-workers demonstrated that the coccoid form of $\mathrm{H}$. pylori remains viable even though culturability was lost in natural fresh-water environments. Interestingly, attempts at reviving the organism from this state have as yet been unsuccessful, ${ }^{90}$ yet experiments in mice have shown reversion to an infective form when exposed to the stomach environment. ${ }^{91}$

Previous studies have also investigated the role of insect vectors in $\mathrm{H}$. pylori spread. House flies (Musca domestica) infected with $H$. pylori could transmit $H$. pylori for up to $30 \mathrm{~h}^{92}$ and $H$. pylori DNA could be amplified from the abdomens of wild flies. ${ }^{4}$ However, $H$. pylori could not be recovered from wild flies exposed to human feces naturally or artificially infected with $H$. pylori. ${ }^{93}$ In addition, a study looking at the impact of the eradication of flies (as part of the 'Flies for the eyes' trachoma study) on $H$. pylori infection rates in an area of high prevalence found that the control of flies did not prevent infection with $H$. pylori, suggesting that flies are not important in $H$. pylori transmission. ${ }^{94}$

The vector potential of cockroaches has also been assessed. Imamura et al ${ }^{10}$ cultured $H$. pylori from the stools of cockroaches for $24 \mathrm{~h}$ and detected $H$. pylori DNA for up to 7 days after experimental exposure to viable $H$. pylori cultures. They suggested that this might represent a mode of transmission in poor socioeconomic environments. ${ }^{10}$

In conclusion, the potential exists for abiotic and biotic reservoirs to contribute to transmission of $H$. pylori. However, attempts at understanding these contributions are limited by the inability to culture $H$. pylori from such reservoirs. The existence of a viable but non-culturable form that might revert to infective $H$. pylori when exposed to the stomach environment should be investigated to determine the role of these reservoirs in the transmission of $H$. pylori.

\section{Transmission pathways}

A general trend observed in studies of transmission pathways in developed countries is that of intrafamilial transmission, particularly involving mothers (Table 1). ${ }^{18,20,33}$ and 44 Such results are also supported by high-resolution sequencing methods. ${ }^{23}$ and 24 Therefore, transmission studies in developed countries are not susceptible to the low resolution of presence/absence methods on which the conclusions of a majority of studies are founded (Table 1). Transmission studies in developing countries also support the role of intrafamilial transmission, including mothers. However, as the prevalence of $H$. pylori is linked to low socioeconomic conditions, ${ }^{12,13}$ and 14 the use of presence/absence methods to infer transmission is questionable. In developed countries, where prevalence is substantially lower, ${ }^{54}$ inference methods that simply detect the presence of $H$. pylori in parents and children might be sufficient to describe intrafamilial transmission pathways. However, in developing countries, where prevalence reaches epidemic proportions, ${ }^{7,}{ }^{* 17,41}$ and ${ }^{*} 54$ the mere observation of the presence of $H$. pylori is not sufficient to infer the direct transmission pathway. In such cases, high-resolution molecular methods are required to identify sharing of strains between individuals for the inference of transmission pathways. 


\section{Table 1.}

The role of intra- versus interfamilial transmission of $H$. pylori as inferred from published transmission studies.

\begin{tabular}{|c|c|}
\hline & Citation \\
\hline \multicolumn{2}{|l|}{ Presencelabsence methods } \\
\hline Parents in developing and asymptomatic study populations & 121 and 122 \\
\hline Siblings in developing and asymptomatic study populations & 41 \\
\hline Parents and siblings in developing symptomatic study populations & 123 \\
\hline Mothers in developed and asymptomatic study populations & $18,20,33,44$ and 124 \\
\hline Parents in developed and asymptomatic study populations & $18,95,124$ and 125 \\
\hline \multicolumn{2}{|l|}{ Molecular methods (L, M, H) } \\
\hline $\begin{array}{l}\text { Parents and siblings in developing and symptomatic study } \\
\text { populations }\end{array}$ & $126(\mathrm{M})$ \\
\hline Mothers in developed and symptomatic study populations & 127,128 and $129(\mathrm{M})$ \\
\hline Parents in developed and symptomatic study populations & 23 and $24(\mathrm{H}), 130(\mathrm{M})$ \\
\hline Siblings in developed and symptomatic study populations & $\begin{array}{l}23 \text { and } 24(\mathrm{H}), 127(\mathrm{M}), 130 \\
(\mathrm{M})\end{array}$ \\
\hline Mothers in developed and asymptomatic study populations & $131(\mathrm{M})$ \\
\hline $\begin{array}{l}\text { Parents and the community in developed asymptomatic study } \\
\text { populations }\end{array}$ & $95(\mathrm{~L})$ \\
\hline
\end{tabular}

In each case the major transmission pathway is presented. Studies are grouped according to methods used, health status, and socioeconomic status of the study population. Resolutions of studies using molecular methods are indicated by low $(\mathrm{L})$, mid $(\mathrm{M})$, and high $(\mathrm{H})$.

Studies in developing countries ${ }^{* 17}$ and 95 have identified the extrafamilial community as an important component of $H$. pylori transmission. Given that the most likely route of infection involves person-toperson contact, the detection of extrafamilial transmission pathways in developing countries with poor hygiene, large families, and extensive social interaction is not surprising. Similarly, evidence for increased prevalence of infection between $H$. pylori-positive spouses ${ }^{40,} 96$ and 97 suggests a person-toperson route of transmission. However, most studies evaluating spouses failed to find a significant effect of infected spouses on prevalence, ${ }^{7,80,98,99}$ and 100 probably the result of an early age of acquisition and little evidence for subsequent infection in adulthood. ${ }^{65,99}$ and 100 
As there are disparities in the inference of $H$. pylori transmission in developed and developing countries, it is necessary that transmission studies in countries in developing countries satisfy three criteria: (1) study population; (2) biochemical/molecular methods; and (3) analytical methods. The choice and structure of study population determines the power of a transmission analysis. Several transmission studies, in both developing and developed countries, are based on symptomatic individuals (see Table 1) who might or might not be undergoing antibiotic treatment. Inferences from such studies are flawed because antibiotic treatment results in the unnatural elimination of $H$. pylori from the host. Furthermore, study populations that are biased towards infected or symptomatic individuals can result in alternative transmission pathways being overlooked. ${ }^{101}$ Other factors to consider in relation to study population are prevalence and the structure of the study population.

When using high-resolution molecular methods that allow strains to be matched at the nucleotide level, higher prevalence in the study population is favored because comparatively more transmission events are observable. Further, study populations based on extended pedigrees are preferred because multiple familial relationship categories can be evaluated simultaneously, whereas studies directed at only mothers and their children, for example, are limited in scope. With regard to suitable molecular methods, it is necessary to use high-resolution DNA sequencing methods for the inference of transmission. Furthermore, the choice of genes is likely to influence interpretations. Several $H$. pylori virulence (vacA) and mobility genes (flaA, flaB) might be under strong selective pressure, ${ }^{102}$ which could result in the inference of shared strains between individuals that are not the result of common ancestry, but rather convergent or parallel evolution. Therefore, housekeeping genes ( $g / m M$, urel, ureC) that are more likely to be selectively neutral ${ }^{102}$ are favored.

Finally, the analytical approach used in a transmission study is likely to influence inference of transmission, given high levels of mutation, recombination, and the possibility for these processes to cause deviations between strains of shared ancestry between the times of infection and subsequent sampling.

To date, these criteria have been fulfilled in a transmission study in developing countries. This study uses high-resolution nucleotide housekeeping gene sequences in a pedigree-based study population with a high prevalence of $\mathrm{H}$. pylori. ${ }^{17}$ Simulation modeling incorporating mutational and recombination sequence changes between the times of infection and sampling was used to evaluate the most likely route of transmission between individuals, given the observed data. The results from this study indicate that transmission scenarios involving a high probability of vertical transmission - either mother-child or father-child - were most unlikely given the observed distribution of sequence divergences (Figure 3 ). ${ }^{17}$ This is in stark contrast to the suite of studies from developed countries, which suggest mother-child interactions as the predominant transmission route (see Table 1). However, consideration of the molecular methods used and the prevalence in the study population suggests that the results agree with a permissive mode of transmission whereby an individual is most likely to acquire infection from those with which he/she is in close social contact. 

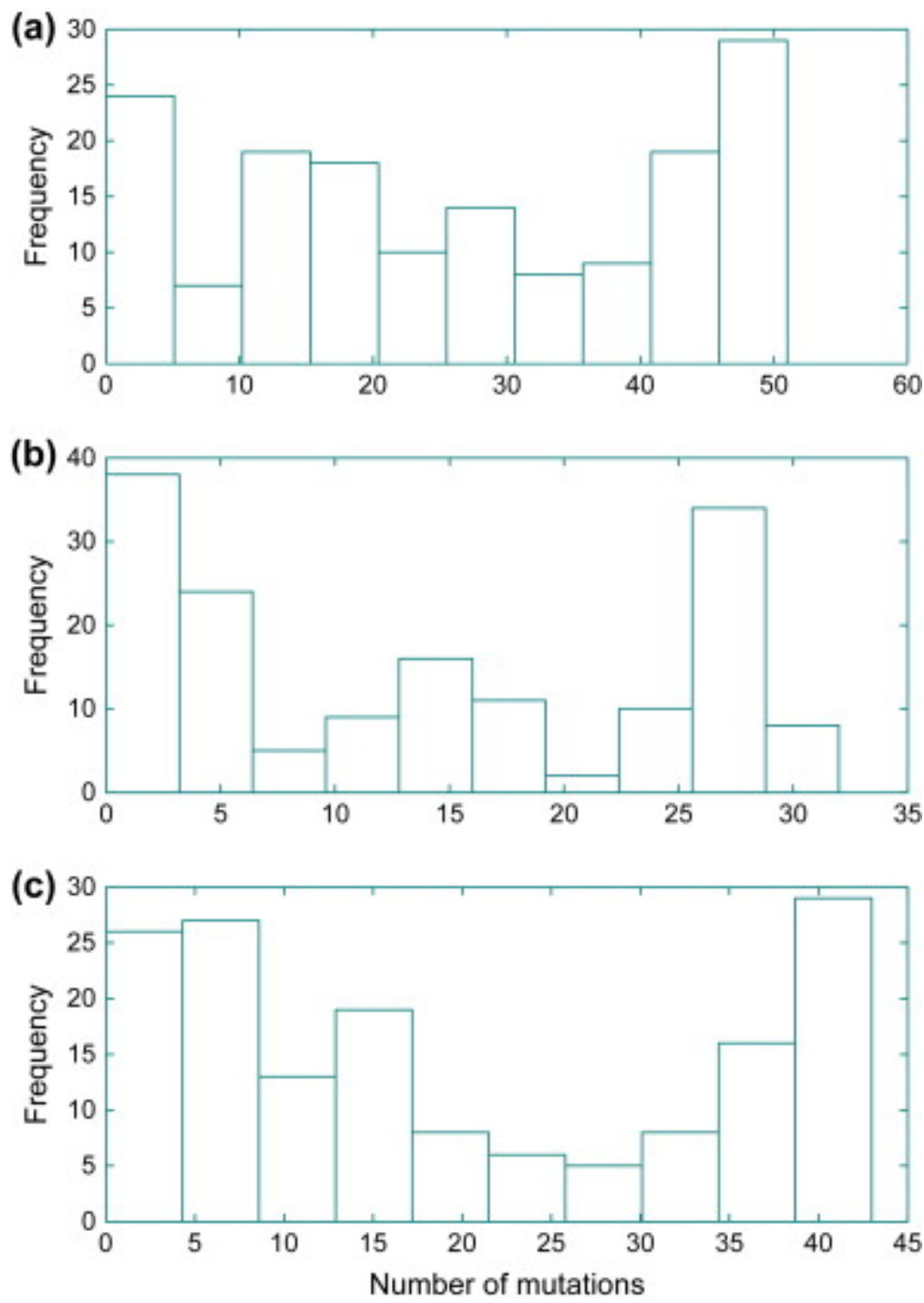

Figure 3. Pairwise within-household mismatch distributions for three genes sequenced from multiple pedigrees. ${ }^{17}$ (a) mutY; (b) ureC; (c) urel. Distributions represent the pairwise differences, in number of mutations between individuals, between individuals of a household. Distributions are bimodal, with modes at both low and high levels of sequence divergence, indicating the role of both familial and community-related transmission.

\section{Multiple strains, host immunity and the host-pathogen interaction}

Thus far, we have reviewed the current knowledge regarding the transmission of $H$. pylori. However, one potential confounding factor in the inference of transmission from high-resolution genetic studies is the effect of infection with multiple strains and the development of the host immune response. Here, we briefly review the evidence for multiple infections, the development of immune response, and the potential effects these may have on the inference of transmission pathways.

If a microbial infection is to persist in a human host it needs to be able to evade the host's immune response and avoid clearance by the immune system. Transient $H$. pylori infections with clearance have been well described. ${ }^{58,66}$ and 67 This implies that persistence of infection is not the inevitable consequence of exposure to $H$. pylori. The ability of $H$. pylori to persist in the hostile environment of the stomach depends on the organism's ability to rapidly adapt to its new environment, off-set against the ability of the immune response to rapidly clear the infection. ${ }^{103}$ and 104 What determines susceptibility to persistence of infection after initial exposure remains unknown. 
After acquisition, $H$. pylori colonises the superficial glycoprotein-rich mucous layer of the stomach, avoiding invasion of the host and, in the process, also avoiding the immune response. ${ }^{103}$ and 105 Components of the innate immune response, e.g. the Toll-like receptors that recognise pathogenassociated molecular patterns, are thus less stimulated by $H$. pylori, which dampens the initial immune response. Further, lipopolysaccharide (LPS) of $H$. pylori elicits virtually no immune response. ${ }^{106}$ This sets the stage for initial colonization. Eventual bacterial interaction leads to the transcription of $H$. pylori genes associated with the cag pathogenicity island that encodes for a type IV secretion apparatus that allows bacterial proteins to enter the epithelial cell. ${ }^{107}$ and ${ }^{*} 108$ One such protein, CagA, is phosphorylated by hostcell Src kinase, ${ }^{109}$ allowing CagA to interact with several signal-transduction pathways affecting cytoskeletal organization, adhesion, and migration of epithelial cells, and potentially inhibiting apoptosis. ${ }^{110}$ The proposed benefit to the bacterium is access to nutrients released by the affected epithelial cell. $H$. pylori strains might also encode for VacA, which acts as a pore-forming protein capable of causing vacuolization in epithelial cells and of which various polymorphisms exist (s1, s2, m1, m2). ${ }^{111}$ This protein further disrupts membrane integrity and tight junctions, leading to the release of urea and nutrients from epithelial cells. ${ }^{112}$ VagA might also block various components of the immune response. ${ }^{113}$

Inflammation and interaction of bacterial products with effectors at the epithelial interface affect cellular transcription factors associated with the innate immune response, with up-regulation of nuclear factor- $\mathrm{KB}$ (NFKB), interleukin 8 (IL-8), cyclo-oxygenase 2 (COX-2), and other proinflammatory cytokines. ${ }^{114}$ This polarises the immune response towards a Th1 response, further attracting inflammatory cells and $T$ lymphocytes capable of producing interferon y (IFNY) and IL-12. ${ }^{115}$ Despite eventual strong humoral and cellular responses, $H$. pylori is rarely cleared and persists for life. ${ }^{106}$ Several studies have shown that an effective CD4 + T-cell response is required to clear $H$. pylori. $H$. pylori modulates the adaptive immune response by inhibiting CD4 + T-cell proliferation and arresting IL-2 cell-cycle progression. ${ }^{113,116}$ and 117

Thus the process of infection can be summarised as evasion of the host immune response followed by adherence and release of $H$. pylori proteins into epithelial cells. This is facilitated by virulence genes and results in cellular alterations that permit the release of nutrients. Inflammation subsequently persists yet complete eradication is rare, as $H$. pylori modulates the host immune response. It is fundamental to evaluate which of these processes might obscure the correct inference of transmission pathways from high-resolution gene sequences. Here, we discuss these effects before and after the establishment of a steady-state equilibrium, after which one dominant strain appears to persist. Indeed, studies sequencing multiple strains per individual detect substantially lower sequence divergences within individuals than between individuals, ${ }^{* 17,} 24,{ }^{*} 48$ and 118 suggesting a shared common ancestor for multiple strains within individuals.

Very little is known of the within-individual infection dynamics at the time of acquisition and period of rapid bacterial population growth. Changes in the host environment, immune response, and nutrient supply might also drive the emergence of $H$. pylori variants due to selective pressures, and thus cause divergence between strains that share a common ancestor. This notion is supported by studies that show the existence of multiple divergent strains within individuals, detected on the basis of virulence gene sequencing or assay techniques. ${ }^{119}$ and 120 The use of housekeeping genes that are not under selective pressure will preclude this possibility. However, the process by which the bacterium is established within the host is not well understood from the point of view of a host genotype-pathogen interaction. The establishment of $H$. pylori within the host is thought to be dependent on three factors: (1) strain-related pathogenicity; (2) host-strain interactions; or (3) host-related immunity.

Strain-related factors are unlikely to play a role as both cag+ and cag- strains become established within the host. ${ }^{26}$ Indeed, when healthy volunteers were exposed to a cag-pathogenicity-island-negative OipApositive $H$. pylori strain, $90 \%$ became infected after one challenge. ${ }^{26}$

The role of host genotype, and its associated immune response, in allowing $H$. pylori to evade an initial immune response is not well understood. If a particular strain of $H$. pylori has a greater probability of evading a particular host's immune response then it would be expected that family members (including children) of the host would show a similar relationship between $H$. pylori strain type and immune 
response evasion. In such a scenario, transmission events would not be obscured because parents and their offspring, if initially infected with the multiple strains, would show the establishment of the same/or closely related strains. However, if bacterial strain selection within individuals is not host related then the possibility exists for other strains to become established in parents and their offspring, even though they are exposed to a common source of strains. Although, this discussion is speculative it provides the outline for research that could be undertaken to identify the factors that permit strain establishment within individuals.

Finally, purely host-related immunity factors can prevent establishment in some individuals/races. Given that clearance and subsequent reinfection show clear racial differences, the possibility of such hostrelated factors in promoting or preventing the establishment of $H$. pylori should not be ignored.

Several paired-sample studies support the notion of a single dominant strain, ${ }^{46,47 \text { and }}{ }^{*} 48$ in which changes observed over time are the result of mutations and intragenomic recombination from a single common ancestor. Given such a scenario, the inference of transmission from gene sequence data is unlikely to be confounded because infection via person-to-person contact results in the same strain becoming established in an infected individual. Mutational and recombination changes between the original and infected strain can be accommodated for using methods described previously. ${ }^{17}$ However, Kraft et $\mathrm{al}^{48}$ discovered that four of six recombination events observed between isolates from the same individuals taken at different times required homologous recombination with DNA from another $H$. pylori genome. Thus the continuous acquisition of new strains is necessary to generate genomic changes in $H$. pylori. Furthermore, these authors conclude that genetic variation that occurs as the result of point mutations, slipped-strand mispairing during DNA replication, and intrachromosomal recombination is less important in generating the genetic diversity on which host adaptation is based. Given such a scenario, the continual uptake of new genetic material into the genome of the dominant host would complicate the inference of transmission from gene sequence data. Indeed, such incorporation of additional genetic material would result in the incorrect inference of transmission. However, the use of multiple unlinked genes precludes this possibility because multiple recombinant events, consistent with each of the genes sequenced would need to occur to confound the inference of transmission.

\section{Summary}

Transmission has been addressed using: (1) prevalence within families; (2) presence in oral and fecal samples; (3) presence in the biotic and abiotic environment; and (4) the observation of shared strains between individuals. Although much research has been conducted on transmission, there is little agreement on which pathways play a dominant role. Indeed, substantial differences in the inference of transmission are found between studies using presence/absence detection methods versus those using high-resolution sequencing methods. Substantial differences are also detected between study populations in developing and developed countries. In this review, we contrast transmission studies under these two principal themes. We conclude that transmission is unlikely to be strictly familial. Studies suggesting otherwise use only presence/absence methods (which are unable to detect strain differences) and study populations in which prevalence is low, thus causing clustering within families. Research conducted in developing countries suggests that the community plays an important role in the transmission of $H$. pylori. This is not surprising given that a person-to-person mode of transmission, facilitated through oral or fecal routes, is most likely. Furthermore, the potential for abiotic and biotic reservoirs to play a role in transmission further supports the notion that individuals might well derive their infection from the community. Increased prevalence in low socioeconomic conditions also supports the community transmission hypothesis. We therefore advocate that transmission should not be considered as being vertical or horizontal but should rather be seen as an infection that is derived from persons with whom children have close social interaction. This is likely to be different in developed and developing countries and therefore accounts for the differences observed. 


\section{Practice Points}

- the dynamics of $H$. pylori transmission differ between developing and developed nations

- the methods used to infer transmission affect the certainty of inference

- H. pylori is transmitted from person to person via gastro-oral or fecal pathways; the fecal route probably plays a greater role

- the role of the abiotic and biotic environments is not well characterised

\section{Research agenda}

- the role of coccoid forms, and their ability to revert back to infective $H$. pylori, needs to be investigated

- the dynamics of strain-host interaction at the time of acquisition, before the onset of a steadystate equilibrium, needs to be understood

\section{References}

1 K.J. Goodman, P. Correa and H.J.T. Aux et al., Helicobacter pylori infection in the Colombian Andes: a population-based study of transmission pathways, Am J Epidemiol 144 (1996), pp. 290-299.

*2 S. Kabir, Detection of Helicobacter pylori DNA in feces and saliva by polymerase chain reaction: a review, Helicobacter 9 (2004), pp. 115-123.

*3 S.A. Dowsett and M.J. Kowolik, Oral Helicobacter pylori: can we stomach it?, Crit Rev Oral Biol Med 14 (2003), pp. $226-233$.

4 P. Grubel, L. Huang and N. Masubuchi et al., Detection of Helicobacter pylori DNA in houseflies (Musca domestica) on three continents, Lancet 352 (1998), pp. 788-789.

5 M. Velazquez and J.M. Feirtag, Helicobacter pylori: characteristics, pathogenicity, detection methods and mode of transmission implicating foods and water, Int J Food Microbiol 53 (1999), pp. 95-104.

6 R.J. Hopkins, P.A. Vial and C. Ferreccio et al., Seroprevalence of Helicobacter in Chile: vegetables may serve as one route of transmission, J Infect Dis 168 (1993), pp. 222-226.

7 Y. Akcan, S. Ersan and M. Alper et al., The transmission of Helicobacter pylori via exposure to common sources outweighs the person-to-person contact among spouses in developing countries, Am J Gastroenterol 95 (2000), pp. 317-319.

8 K. Hultén, H. Enroth and T. Nyström et al., Presence of Helicobacter species DNA in Swedish water, J Appl Microbiol 85 (1998), pp. 282-286.

9 P.D. Klein, R.H. Gilman and R. Leon-Barua et al., The epidemiology of Helicobacter pylori in Peruvian children between 6 and 30 months of age, Am J Gastroenterol 89 (1994), pp. 2196-2200.

10 S. Imamura, M. Kita and Y. Yamaoka et al., Vector potential of cockroaches for Helicobacter pylori infection, Am J Gastroenterol 98 (2003), pp. 1500-1503.

11 C. Burucoa, V. Lhomme and J.L. Fauchere, Performance criteria of DNA fingerprinting methods for typing of Helicobacter pylori isolates: experimental results and meta-analysis, J Clin Microbiol 37 (1999), pp. 4071-4080. 
12 J.E. Everhart, Recent developments in the epidemiology of Helicobacter pylori, Gastroenterol Clin North Am 20 (2000), pp. 559-578.

13 J.E.G. Bunn, W.G. MacKay and J.E. Thomas et al., Detection of Helicobacter pylori DNA in drinking water biofilms: implications for transmission in early life, Lett Appl Microbiol 34 (2002), pp. 450-454.

14 S. Suerbaum and P. Michetti, Helicobacter pylori infection, N Engl J Med 347 (2002), pp. 1175-1186.

15 R.A. Alm, L.-S.L. Ling and D.T. Moir et al., Genomic-sequence comparison of two unrelated isolates of the human gastric pathogen Helicobacter pylori, Nature 397 (1999), pp. 176-180.

16 B.J. Olivier, R.P. Bond and W.B. van Zyl et al., Absence of Helicobacter pylori within the Oral Cavities of Members of a Healthy South African Community, J Clin Microbiol 44 (2006), pp. 635-636.

*17 W. Delport, M. Cunningham and B.J. Olivier et al., A population genetics pedigree perspective on the transmission of Helicobacter pylori, Genetics 174 (2006), pp. 2107-2118.

18 Y. Tindberg, C. Bengtsson and F. Granath et al., Helicobacter pylori infection in Swedish School Children: lack of evidence of child-to-child transmission outside the family, Gastroenterology 121 (2001), pp. 310-316.

19 K.S. Samir, B. Martin and B.D. Gold et al., The incidence of Helicobacter pylori acquisition in children of a Canadian first nations community and the potential for parent-to-child transmission, Helicobacter 9 (2004), pp. 59-68.

20 D. Rothenbacher, G. Bode and G. Berg et al., Helicobacter pylori among preschool children and their parents: evidence of parent-child transmission, J Infect Dis 179 (1999), pp. 398-402.

21 J.T. Wang, J.C. Sheu and J.T. Lin et al., Direct DNA amplification and restriction pattern analysis of Helicobacter pylori in patients with duodenal ulcer and their families, J Infect Dis 168 (1993), pp. 1544-1548.

22 E.J. Prewett, J. Bickley and R.J. Owen et al., DNA patterns of Helicobacter pylori isolated from gastric antrum, body and duodenum, Gastroenterology 102 (1992), pp. 829-833.

23 R.J. Owen and J. Xerry, Tracing clonality of Helicobacter pylori infecting family members from analysis of DNA sequences of three housekeeping genes (urel, atpA and ahpC), deduced amino acid sequences, and pathogenicity-associated markers (cagA and vacA), J Med Microbiol 52 (2003), pp. 515-524.

24 J. Raymond, J.-M. Thiberge and C. Chevalier et al., Genetic and transmission analysis of Helicobacter pylori strains within a family, Emerg Infect Dis 10 (2004), pp. 1816-1821.

25 H.M. Mitchell, Y.Y. Li and P.J. Hu et al., Epidemiology of Helicobacter pylori in southern China: identification of early childhood as the critical period for acquisition, J Infect Dis 166 (1992), pp. 149-153.

26 Z.Z. Nurgalieva, M.E. Conner and A.R. Opekun et al., B-cell and T-cell immune responses to experimental Helicobacter pylori infection in humans, Infect Immun 73 (2005), pp. 2999-3006.

*27 K.J. Goodman, K. O'Rourke and R.S. Day et al., Dynamics of Helicobacter pylori infection in a US-Mexico cohort during the first two years of life, Int J Epidemiol 34 (2005), pp. 1348-1355.

28 J. Dominguez, M. Forne and S. Blanco et al., Comparison of a monoclonal with a polyclonal antibody based enzyme immunoassay stool test in diagnosing Helicobacter pylori infection before and after eradication therapy, Aliment Pharmacol Ther 23 (2006), pp. 1735-1740.

29 A.F. Goddard and R.P. Logan, Urea breath tests for detecting Helicobacter pylori, Aliment Pharmacol Ther 11 (1997), pp. $641-649$.

30 D. Vaira, J. Holton and C. Ricci et al., Review article: Helicobacter pylori infection from pathogenesis to treatment-a critical reappraisal, Aliment Pharmacol Ther 16 (2002) (supplement 4), pp. 105-113.

31 C.L. Clayton, H. Kleanthous and P.J. Coates et al., Sensitive detection of Helicobacter pylori by using polymerase chain reaction, J Clin Microbiol 30 (1992), pp. 192-200. 
32 J.-J. Lu, C.-L. Perng and R.-Y. Shyu et al., Comparison of five PCR methods for detection of Helicobacter pylori DNA in gastric tissues, J Clin Microbiol 37 (1999), pp. 772-774.

33 M. Weyermann, G. Adler and H. Brenner et al., The mother as a source of Helicobacter pylori infection, Epidemiology 17 (2006), pp. 332-334.

34 N.S. Taylor, J.G. Fox and N.S. Akopyants et al., Construction of a Helicobacter pylori genome map and demonstration of diversity at the genome level, J Bacteriol 174 (1992), pp. 6800-6806.

35 M.J. Struelens and Members of the European Study Group on Epidemiological Markers (ESGEM) otESfCMalDE, Consensus guidelines for appropriate use and evaluation of microbial epidemiologic typing systems, Clin Microbiol Infect 2 (1996), pp. 2-11.

36 A.Y. Davin-Regli, R.N. Abed and C. Charrel et al., Variations in DNA concentrations significantly affect the reproducibility of RAPD fingerprint patterns, Res Microbiol 146 (1995), pp. 561-568.

37 J.R. Meunier and P.A.D. Grimont, Factors affecting reproducibility of random amplified polymorphic DNA fingerprinting, Res Microbiol 144 (1993), pp. 373-379.

38 K.D. Tyler, G. Wang and S.D. Tyler et al., Factors affecting reliability and reproducibility of amplification-based DNA fingerprinting of representative bacterial pathogens, J Clin Microbiol 35 (1997), pp. 339-346.

*39 D. Falush, C. Kraft and N.S. Taylor et al., Recombination and mutation during long-term gastric colonization by Helicobacter pylori: estimates of clock rates, recombination size, and minimal age, Proc Natl Acad Sci USA 98 (2001), pp. 15056-15061.

$40 \mathrm{H}$. Brenner, M. Weyermann and D. Rothenbacher, Clustering of Helicobacter pylori infection in couples: differences between high- and low-prevalence population groups, Ann Epidemiol 16 (2006), pp. 516-520.

41 K.J. Goodman and P. Correa, Transmission of Helicobacter pylori among siblings, Lancet 355 (2000), pp. 358-362.

42 G.A. Rocha, A.M.C. Rocha and L.D. Silva et al., Transmission of Helicobacter pylori infection in families of preschool-aged children from Minas Gerais, Brazil, Trop Med Int Health 8 (2003), pp. 987-991.

43 M.N. Rodrigues, D.M. Queiroz and J.G. Bezerra Filho et al., Prevalence of Helicobacter pylori infection in children from an urban community in north-east Brazil and risk factors for infection, Eur J Gastroenterol Hepatol 16 (2004), pp. $201-205$.

$44 \mathrm{H}$. Brenner, D. Rothenbacher and G. Bode et al., Parental history of gastric or duodenal ulcer and prevalence of Helicobacter pylori infection in preschool children: evidence for mother-infant transmission, BMJ 316 (1998), p. 665.

45 V. Prouzet-Mauleon, M.A. Hussain and H. Lamouliatte et al., Pathogen evolution in vivo: genome dynamics of two isolates obtained 9 years apart from a duodenal ulcer patient infected with a single Helicobacter pylori strain, J Clin Microbiol 43 (2005), pp. 4237-4241.

46 E.J. Kuipers, D.A. Israel and J.G. Kusters et al., Quasispecies development of Helicobacter pylori observed in paired isolates obtained years apart from the same host, J Infect Dis 181 (2000), pp. 273-282.

47 A. Lundin, B. Bjorkholm and I. Kupershmidt et al., Slow genetic divergence of Helicobacter pylori strains during long-term colonization, Infect Immun 73 (2005), pp. 4818-4822.

*48 C. Kraft, A. Stack and C. Josenhans et al., Genomic changes during chronic Helicobacter pylori infection, J Bacteriol 188 (2006), pp. 249-254.

49 L.M. Brown, T.L. Thomas and J.-L. Ma et al., Helicobacter pylori infection in rural China: demographic, lifestyle and environmental factors, Int J Epidemiol 31 (2002), pp. 638-645.

50 P.A. Noone, E.R. Waclawski and A.D. Watt, Are endoscopy nurses at risk of infection with Helicobacter pylori from their work?, Occup Med 56 (2006), pp. 122-128.

51 A. Özen, D. Ertem and E. Pehlivanoglu, Natural history and symptomatology of Helicobacter pylori in childhood and factors determining the epidemiology of infection, J Pediatr Gastroenterol Nutr 42 (2006), pp. 398-404. 
52 S.C. Fiedorek, H.M. Malaty and D.L. Evans et al., Factors influencing the epidemiology of Helicobacter pylori infection in children, Pediatrics 88 (1991), pp. 578-582.

53 P. Moayyedi, A.T.R. Axon and R. Feltbower et al., Relation of adult lifestyle and socioeconomic factors to the prevalence of Helicobacter pylori infection, Int J Epidemiol 31 (2002), pp. 624-631.

*54 J.R.W. Frenck and J. Clemens, Helicobacter in the developing world, Microb Infect 5 (2003), pp. 705-713.

55 M.M. Rahman, D. Mahalanabis and S.A. Sarker et al., Helicobacter pylori colonization in infants and young children is not necessarily associated with diarrhoea, J Trop Pediatr 44 (1998), pp. 283-287.

56 J. Clemens, M.J. Albert and M. Rao et al., Sociodemographic, hygienic and nutritional correlates of Helicobacter pylori infection of young Bangladeshi children, Pediatr Infect Dis J 15 (1996), pp. 1113-1118.

57 J.E. Thomas, A. Dale and M. Harding et al., Interpreting the 13C-urea breath test among a large population of young children from a developing country, Pediatr Res 46 (1999), pp. 147-151.

58 M. Granstrom, Y. Tindberg and M. Blennow, Seroepidemiology of Helicobacter pylori infection in a cohort of children monitored from 6 months to 11 years of age, J Clin Microbiol 35 (1997), pp. 468-470.

59 H.M. Malaty, A. El-Kasabany and D.Y. Graham et al., Age at acquisition of Helicobacter pylori infection: a follow-up study from infancy to adulthood, Lancet 359 (2002), pp. 931-935.

60 M.K. Glynn, C.R. Friedman and B.D. Gold et al., Seroincidence of Helicobacter pylori infection in a cohort of rural Bolivian children: acquisition and analysis of possible risk factors, Clin Infect Dis 35 (2002), pp. 1059-1065.

61 A. Kindermann, H. Demmelmair and B. Koletzko et al., Influence of age on 13C-urea breath test results in children, J Pediatr Gastroenterol Nutr 30 (2000), pp. 85-91.

62 C. Imrie, M. Rowland and B. Bourke et al., Limitations to carbon 13-labeled urea breath testing for Helicobacter pylori in infants, J Pediatr 139 (2001), pp. 734-737.

63 M. Rowland, L. Daly and M. Vaughan et al., Age-specific incidence of Helicobacter pylori, Gastroenterology 130 (2006), pp. 65-72.

64 M.L. Replogle, W. Kasumi and K.B. Ishikawa et al., Increased risk of Helicobacter pylori associated with birth in wartime and post-war Japan, Int J Epidemiol 25 (1996), pp. 210-214.

65 N. Banatvala, K. Mayo and F. Megraud et al., The cohort effect and Helicobacter pylori, J Infect Dis 168 (1993), pp. $219-221$.

66 M. Kivi and Y. Tindberg, Helicobacter pylori occurrence and transmission: a family affair, Scand J Infect Dis 38 (2006), pp. 407-417.

67 T. Kumagai, H.M. Malaty and D.Y. Graham et al., Acquisition versus loss of Helicobacter pylori infection in Japan: results from an 8-year birth cohort study, J Infect Dis 178 (1998), pp. 717-721.

$68 \mathrm{~K}$. Muhsen, A. Athamna and M. Athamna et al., Prevalence and risk factors of Helicobacter pylori infection among healthy 3to 5-year-old Israeli Arab children, Epidemiol Infect 134 (2006), pp. 990-996.

$69 \mathrm{~J}$. Parsonnet, H. Shmuely and T. Haggerty, Fecal and oral shedding of Helicobacter pylori from healthy infected adults, Jama 282 (1999), pp. 2240-2245.

70 Q. Song, T. Lange and A. Spahr et al., Characteristic distribution pattern of Helicobacter pylori in dental plaque and saliva detected with nested PCR, J Med Microbiol 49 (2000), pp. 349-353.

71 N. Banatvala, C.R. Lopez and R. Owen et al., Helicobacter pylori in dental plaque, Lancet 341 (1993), p. 8841.

72 P.G. Hardo, A. Tugnait and F. Hassan et al., Helicobacter pylori infection and dental care, Gut 37 (1995), pp. 44-46.

73 A.M. Nguyen, L. Engstrand and R.M. Genta et al., Detection of Helicobacter pylori in dental plaque by reverse transcriptionpolymerase chain reaction, J Clin Microbiol 31 (1993), pp. 783-787. 
74 Q. Song, A. Spahr and R.M. Schmid et al., Helicobacter pylori in the oral cavity: high prevalence and great DNA diversity, Dig Dis Sci 45 (2000), pp. 2162-2167.

75 C. Goosen, J. Theron and M. Ntsala et al., Evaluation of a novel heminested PCR assay based on the phosphoglucosamine mutase gene for detection of Helicobacter pylori in saliva and dental plaque, J Clin Microbiol 40 (2002), pp. 205-209.

76 T.K. Chow, J.R. Lambert and M.L. Wahlqvist et al., Helicobacter pylori in Melbourne Chinese immigrants: evidence for oraloral transmission via chopsticks, J Gastroenterol Hepatol 10 (1995), pp. 562-569.

77 F. Megraud, Transmission of Helicobacter pylori: faecal-oral versus oral-oral route, Aliment Pharmacol Ther 9 (1995) (supplement 2), pp. 85-91.

78 G. Bode, F. Mauch and P. Malfertheiner, The coccoid forms of Helicobacter pylori. Criteria for their viability, Epidemiol Infect 111 (1993), pp. 483-490.

79 C. Li, T. Ha and D.A. Ferguson Jr. et al., A newly developed PCR assay of $H$. pylori in gastric biopsy, saliva, and feces. Evidence of high prevalence of $H$. pylori in saliva supports oral transmission, Dig Dis Sci 41 (1996), pp. 2142-2149.

80 G.I. Perez-Perez, S.S. Witkin and M.D. Decker et al., Seroprevalence of Helicobacter pylori infection in couples, J Clin Microbiol 29 (1991), pp. 642-644.

81 A.F. Cutler and T.T. Schubert, Patient factors affecting Helicobacter pylori eradication with triple therapy, Am J Gastroenterol 88 (1993), pp. 505-509.

82 J.E. Thomas, G.R. Gibson and M.K. Darboe et al., Isolation of Helicobacter pylori from human faeces, Lancet 340 (1992), pp. 8829-8830.

83 H.M. Mitchell, A. Lee and J. Carrick, Increased incidence of Campylobacter pylori infection in gastroenterologists: further evidence to support person to person transmission, Scand J Gastroenterol 24 (1989), pp. 396-400.

84 S.K. Lin, J.R. Lambert and M.A. Schembri et al., Helicobacter pylori prevalence in endoscopy and medical staff, J Gastroenterol Hepatol 9 (1994), pp. 319-324.

85 H.M. Malaty, D.J. Evans and K. Abramovitch et al., Helicobacter pylori infection in dental workers: a seroepidemiology study, Am J Gastroenterol 87 (1992), pp. 1728-1731.

86 S.K. Lin, I. Lambert and M.A. Schembri et al., The prevalence of Helicobacter pylori in practising dental staff and dental students, Aust Dent J 43 (1998), pp. 35-39.

$87 \mathrm{H}$. Enroth and L. Engstrand, Immunomagnetic separation and PCR for detection of Helicobacter pylori in water and stool specimens, J Clin Microbiol 33 (1995), pp. 2162-2165.

88 Y. Lu, T.E. Redlinger and R. Avitia et al., Isolation and genotyping of Helicobacter pylori from untreated municipal wastewater, Appl Environ Microbiol 68 (2002), pp. 1436-1439.

89 M. Shahamat, U. Mai and C. Paszko-Kolva et al., Use of autoradiography to assess viability of Helicobacter pylori in water, Appl Environ Microbiol 59 (1993), pp. 1231-1235.

90 B.L. Adams, T.C. Bates and J.D. Oliver, Survival of Helicobacter pylori in a natural freshwater environment, Appl Environ Microbiol 69 (2003), pp. 7462-7466.

91 P. Alejung, H.O. Nilsson and X. Wang et al., Gastrointestinal colonisation of BALB/cA mice by Helicobacter pylori monitored by heparin magnetic separation, FEMS Immunol Med Microbiol 13 (1996), pp. 303-309.

92 P. Grubel, J.S. Hoffman and F.K. Chong et al., Vector potential of houseflies (Musca domestica) for Helicobacter pylori, J Clin Microbiol 35 (1997), pp. 1300-1303.

93 M.S. Osato, K. Ayub and H.H. Le et al., Houseflies are an unlikely reservoir or vector for Helicobacter pylori, J Clin Microbiol 36 (1998), pp. 2786-2788. 


\section{openUP}

94 S.J. Allen, J.E. Thomas and N.D. Alexander et al., Flies and Helicobacter pylori infection, Arch Dis Child 89 (2004), pp. 1037-1038.

95 B.L. Ng, H.C. Ng and K.T. Goh et al., Helicobacter pylori in familial clusters based on antibody profile, FEMS Immunol Med Microbiol 30 (2001), pp. 139-142.

$96 \mathrm{H}$. Brenner, D. Rothenbacher and G. Bode et al., Active infection with Helicobacter pylori in healthy couples, Epidemiol Infect 122 (2000), pp. 91-95.

97 V. Singh, B. Trikha and K. Vaiphei et al., Helicobacter pylori: evidence for spouse-to-spouse transmission, J Gastroenterol Hepatol 14 (1999), pp. 519-522.

98 C.-H. Kuo, S.-K. Poon and Y.-C. Su et al., Heterogeneous Helicobacter pylori isolates from H. pylori infected couples in Taiwan, J Infect Dis 180 (1999), pp. 2064-2068.

99 W. Luman, Y. Zhao and H.S. Ng et al., Helicobacter pylori infection is unlikely to be transmitted between partners: evidence from genotypic study in partners of infected patients, Eur J Gastroenterol Hepatol 14 (2002), pp. 521-528.

$100 \mathrm{~J}$. Suzuki, H. Muraoka and I. Kobayasi et al., Rare incidence of interspousal transmission of Helicobacter pylori in asymptomatic individuals in Japan, J Clin Microbiol 37 (1999), pp. 4174-4176.

101 M. Kivi, A.L.V. Johansson and A. Salim et al., Accomodation of additional non-randomly sampled cases in a study of Helicobacter pylori infection in families, Statist Med 24 (2005), pp. 4045-4054.

*102 M. Achtman, T. Azuma and D.E. Berg et al., Recombination and clonal groupings within Helicobacter pylori from different geographical regions, Mol Microbiol 32 (1999), pp. 459-470.

103 K. van Amsterdam, A.H. van Vliet and J.G. Kusters et al., Of microbe and man: determinants of Helicobacter pylori-related diseases, FEMS Microbiol Rev 30 (2006), pp. 131-156.

104 M.J. Blaser, Ecology of Helicobacter pylori in the human stomach, J Clin Invest 100 (1997), pp. 759-762.

105 S. Schreiber, M. Konradt and C. Groll et al., The spatial orientation of Helicobacter pylori in the gastric mucus, Proc Natl Acad Sci USA 101 (2004), pp. 5024-5029.

*106 M.J. Blaser and J.C. Atherton, Helicobacter pylori persistence: biology and disease, J Clin Invest 113 (2004), pp. 321-333.

107 S. Odenbreit, J. Puls and B. Sedlmaier et al., Translocation of Helicobacter pylori CagA into gastric epithelial cells by type IV secretion, Science 287 (2000), pp. 1497-1500.

*108 G. Rieder, W. Fischer and R. Haas, Interaction of Helicobacter pylori with host cells: function of secreted and translocated molecules, Curr Opin Microbiol 8 (2005), pp. 67-73.

109 M. Selbach, S. Moese and C.R. Hauck et al., Src is the kinase of the Helicobacter pylori CagA protein in vitro and in vivo, $J$ Biol Chem 277 (2002), pp. 6775-6778.

110 M. Selbach, S. Moese and R. Hurwitz et al., The Helicobacter pylori CagA protein induces cortactin dephosphorylation and actin rearrangement by c-Src inactivation, Embo J 22 (2003), pp. 515-528.

111 J.C. Atherton, P. Cao and R.M. Peek et al., Mosaicism in vacuolating cytotoxin alleles of Helicobacter pylori. Association of specific vacA types with cytotoxin production and peptic ulceration, J Biol Chem 270 (1995), pp. 17771-17777.

112 F. Tombola, L. Morbiato and G. Del Giudice et al., The Helicobacter pylori VacA toxin is a urea permease that promotes urea diffusion across epithelia, J Clin Invest 108 (2001), pp. 929-937.

113 M.S. Sundrud, V.J. Torres and D. Unutmaz et al., Inhibition of primary human T cell proliferation by Helicobacter pylori vacuolating toxin (VacA) is independent of VacA effects on IL-2 secretion, Proc Natl Acad Sci USA 101 (2004), pp. 7727-7732.

114 L. Deml, M. Aigner and J. Decker et al., Characterization of the Helicobacter pylori cysteine-rich protein A as a T-helper cell type 1 polarizing agent, Infect Immun 73 (2005), pp. 4732-4742. 


\section{openUP}

115 A. Amedei, A. Cappon and G. Codolo et al., The neutrophil-activating protein of Helicobacter pylori promotes Th1 immune responses, J Clin Invest 116 (2006), pp. 1092-1101.

116 F. Meyer, K.T. Wilson and S.P. James, Modulation of innate cytokine responses by products of Helicobacter pylori, Infect Immun 68 (2000), pp. 6265-6272.

117 B. Gebert, W. Fischer and E. Weiss et al., Helicobacter pylori vacuolating cytotoxin inhibits T lymphocyte activation, Science 301 (2003), pp. 1099-1102.

118 D.A. Israel, N. Salama and U. Krishna et al., Helicobacter pylori genetic diversity within the gastric niche of a single human host, Proc Natl Acad Sci USA 98 (2001), pp. 14625-14630.

119 R. Morales-Espinosa, G. Castillo-Rojas and G. Gonzalez-Valencia et al., Colonization of Mexican patients by multiple Helicobacter pylori strains with different vacA and cagA genotypes, J Clin Microbiol 37 (1999), pp. 3001-3004.

120 C. Ghose, G.I. Perez-Perez and L.J. van Doorn et al., High frequency of gastric colonization with multiple Helicobacter pylori strains in Venezuelan subjects, J Clin Microbiol 43 (2005), pp. 2635-2641.

121 J.-L. Ma, W.-C. You and M.H. Gail et al., Helicobacter pylori infection and mode of transmission in a population at high risk of stomach cancer, Int J Epidemiol 27 (1998), pp. 570-573.

122 M.N. Rodrigues, D.M.M. Queiroz and A.B.C. Braga et al., History of breastfeeding and Helicobacter pylori infection in children: results of a community-based study from northeastern Brazil, Trans R Soc Trop Med Hygiene 100 (2006), pp. 470475 .

123 B. Drumm, G. Perez-Perez and M.J. Blaser et al., Intrafamilial clustering of Helicobacter pylori infection, N Engl J Med 322 (1990), pp. 359-363.

124 D. Rothenbacher, M. Winkler and T. Gonser et al., Role of infected patients in transmission of Helicobacter pylori to their children, Pediatr Infect Dis J 21 (2002), pp. 674-679.

125 P. Dominici, S. Bellentani and A.R. Di Biase et al., Familial clustering of Helicobacter pylori infection: population based study, BMJ 319 (1999), pp. 537-541.

126 K.B. Bamford, J. Bickley and J.S. Collins et al., Helicobacter pylori: comparison of DNA fingerprints provides evidence for intrafamilial infection, Gut 34 (1993), pp. 1348-1350.

127 M. Kivi, Y. Tindberg and M. Sorberg et al., Concordance of Helicobacter pylori strains within families, J Clin Microbiol 41 (2003), pp. 5604-5608.

128 T. Shimizu, S. Oguchi and Y. Yamashiro et al., Helicobacter pylori transmission between a boy with duodenal ulcer and his father, Pediatr Infect Dis J 18 (1999), pp. 655-656.

129 T. Shimizu, Y. Yarita and K. Kaneko et al., Case of intrafamilial Helicobacter pylori reinfection after successful eradication therapy, Pediatr Infect Dis J 19 (2000), pp. 901-903.

130 S.-R. Han, H.-C.E. Zschausch and H.-G.W. Meyer et al., Helicobacter pylori: clonal population structure and restricted transmission within families revealed by molecular typing, J Clin Microbiol 38 (2000), pp. 3646-3651.

131 M. Konno, N. Fujii and S.-I. Yokota et al., Five-year follow-up study of mother-to-child transmission of Helicobacter pylori infection detected by a Random Amplified Polymorphic DNA fingerprinting method, J Clin Microbiol 43 (2006), pp. 2246-2250. 